\title{
The Use of Touch in Developing A Therapeutic Relationship.
}

David Stonehouse is a Senior Lecturer with the Faculty of Health and Social Care at Edge Hill University.

\section{Abstract.}

Within this article the author will be discussing the use of touch within health and social care. The different types of touch will firstly be defined before moving on to examine the many benefits that expressive touch can bring to the health and social care role and to developing a supportive therapeutic relationship between the support worker and their patient. Relevant sections of The Code of Conduct for Healthcare Support Workers and Adult Social Care Workers in England (Skills for Care and Skills for Health, 2013) will be highlighted throughout. The important aspects of communication, compassion and empathy will be explored. Touch is not always appropriate or welcomed by the patient and the support worker must take into account preferences, cultural needs and beliefs whilst also gaining consent.

Key Words: Communication, Compassion, Expressive Touch, Instrumental Touch, Protective Touch, Support Workers, Therapeutic Touch.

\section{$\underline{\text { Introduction }}$}

As a support worker you come into close physical contact with your patients on a daily basis. This contact will inevitably involve touch. It would be impossible to fulfil your duty of care to them if you didn't, through the provision of personal and clinical care. How that touch is negotiated and planned is very important both for the patient and the support worker and if don't correctly can help to develop a good therapeutic relationship.

\section{Different Types of Touch}

Touch can be categorised into three main areas, instrumental, protective and expressive (O'Lynn and Krautscheid, 2011). Most touching will be what is known as instrumental touch. Touch as a result of performing procedures or direct care. For example washing and dressing, changing dressings or taking observations.

Protective touch is when a care giver touches a patient to prevent them from endangering themselves. For example preventing a patient from pulling out a cannula or nasogastric tube, or from hitting themselves. 
The third type of touch and the focus of this article, is one which conveys emotion, support and compassion. This is known as expressive touch. For example holding a dying patients hand or placing a reassuring hand on someone's shoulder. This is probably the most important form of touch in helping to develop the therapeutic relationship with your patient. As Sharples (2013) says it is about letting the patient know that you are there and that you care. Expressive touch has also been categorised as a cathartic intervention (Russell, 1999). This is where through touch you encourage a patient to let go of their emotions and release tension and anxiety.

\section{Therapeutic Touch}

There is also a fourth type of touch known as therapeutic touch. Within the nursing literature this is often wrongly confused with expressive touch. However, therapeutic touch is a complementary therapy whereby the trained support worker uses their hands to facilitate relaxation and healing. Despite the name no actual touching takes place. Kozier et al (2012:200) states it is "based on the concept of human energy fields." The goal is to smooth out or relieve energy congestion over the patient's body and is believed to be helpful in reducing pain and anxiety (Coakley and Barron, 2012) and enhances the healing process of patients who are injured or ill (Kozier et al, 2012). Research has been performed in the areas of oncology (Tabatabaee et al, 2016) and palliative care (Senderovich et al, 2016) highlighting its potential benefits. While Herdtner (2000) reports that studies have shown therapeutic touch to have a calming response which would be beneficial for patients both pre and post operatively and a relaxation response which reduces anxiety, promotes sleep, aids in pain relief and reduces swelling.

\section{Communication.}

Expressive touch can be an important means of communication. Chamley and James (2013:584) identify that it is "a two way process involving feelings and sensation, and indicates a caring or loving relationship." When you place your hand upon another's it transfers warmth and care between the two of you. Craig (2016) states that touch for patients in the later stages of dementia can be very important as physical contact could be their only means of communicating with those around them. Skills for Care (2016) states that touch can also be used in a more practical way to communicate with people who are deaf and visually impaired by signing information directly onto the person's hand.

\section{Compassion}

The second of the $6^{\prime} \mathrm{Cs}$, compassion, immediately after care, shows how fundamental to the work of the support worker this key value is. Expressive touch can be a way of demonstrating this compassion. The Code of Conduct for Healthcare Support Workers and Adult Social Care Workers in England (Skills for Care and Skills for Health, 2013) Section 2.2 states that you must "always treat people with respect and compassion." "Compassion is how care is given through 
relationships based on empathy, respect and dignity - it can also be described as intelligent kindness, and is central to how people perceive their care" (Department of Health, 2012:13). Within the glossary section of the Code of Conduct for Healthcare Support Workers and Adult Social Care Workers in England (Skills for Care and Skills for Health, 2013:11) compassionate care is described as including "dignity and comfort: taking time and patience to listen, explain and communicate; demonstrating empathy, kindness and warmth; care centred around an individual person's needs, involving people in the decisions about their healthcare, care and support." Through the correct use of touch in an expressive way will offer dignity and comfort and demonstrate the support workers kindness, empathy and warmth. As Chambers and Ryder (2009:100) states in many cases touch "is the most effective means of providing human comfort." Russell (2011) discusses the importance that touch can play in helping someone going through loss and bereavement. Often when a patient is experiencing loss it is very hard for the support worker to know what to say. Words can appear meaningless. Often just being there is more important and a reassuring touch can say a thousand words.

\section{Issues of Touch.}

The Code of Conduct for Healthcare Support Workers and Adult Social Care Workers in England (Skills for Care and Skills for Health, 2013) Section 1.6 states that you must maintain and establish appropriate and clear professional boundaries with your patients. This includes knowing when it is not appropriate to use touch or when that touch could be misunderstood by the patient. As Quiddington (2009:65) states "touching a person is a boundary issue, so do not assume that every individual finds being touched acceptable or desirable." Just as it may not be appropriate for a support worker to provide personal intimate care to a patient of the opposite sex then so too expressive touch may not be appropriate. Care needs to be taken as touch can easily be misconstrued and "perceived as a sexual gesture" (Kozier et al, 2012:214).

The Care Certificate (Skills for Care, 2016) Standard 6 Communication states that touch must be undertaken thoughtfully and in a person-centred way. You need to talk to your patient to understand their preferences and also gain their consent to the touching. Failure to gain consent may constitute the criminal or civil offence of battery (Department of Health, 2009). Each patient's wishes and needs will be different and must to be taken into account.

\section{Cultural needs.}

Section 7.1 of The Code of Conduct for Healthcare Support Workers and Adult Social Care Workers in England (Skills for Care and Skills for Health, 2013) states that you must "respect the individuality and diversity of the people who use health and care services, their carers and your colleagues." Through being aware of the needs and wishes of your patients concerning the use of touch will ensure whether it 
is appropriate to use or not. It is very important that cultural wishes and beliefs are taken into account when deciding to touch a patient. Kozier et al (2012:46) identifies that in some cultures "touch is considered magical and because of the belief that the soul can leave the body on physical contact, casual touching is forbidden." In some Asian cultures for example, patting a child on the head is not allowed and only certain adults are allowed to touch the head of others (Kozier et al, 2012).

\section{Conclusion.}

So to conclude, this article has highlighted the importance that expressive touch plays in developing a therapeutic relationship and delivering person centred care. Touch, if done sensitively and appropriately can demonstrate compassion, empathy and kindness and will offer much comfort and support to both patients and their families. However the support worker needs to be mindful of the patient's wishes in regards to touch and always gain consent.

\section{Key Points:}

- As a support worker different types of touch will be used throughout your practice.

- Expressive touch will help develop a therapeutic relationship with your patients and their families.

- Touch helps to demonstrate compassion, empathy and care.

- Consent must always be gained before any touching takes place.

- Cultural needs, preferences and beliefs must be taken into account when touching a patient.

\section{References:}

Chambers C Ryder C (2009) Compassion and Caring in Nursing. Radcliffe Publishing, Oxford.

Chamley C, James G (2013) Pain management - Minimizing the pain experience. In: Brooker C, Waugh A (eds) Nursing Practice: Fundamentals of holistic Care. Mosby Elsevier, London. 563-587.

Coakley A B \& Barron A (2012) Energy Therapies in Oncology Nursing. Seminars in Oncology Nursing. 28(1): 55-63.

Craig G (2016) What Compassion Means: The Person and Family Perspective. In Hewison A \& Sawbridge $Y$ (eds) Compassion in Nursing: Theory, Evidence and Practice. Palgrave Macmillan Education, London. 77-91. 
Department of Health (2009) Reference Guide to Consent for Examination or Treatment. 2nd edn.

https://www.gov.uk/government/uploads/system/uploads/attachment data/file/13829 6/dh $103653 \quad 1$.pdf (accessed 20 November 2016)

Department of Health (2012) Compassion in Practice: Nursing, Midwifery and Care Staff Our Vision and Strategy. https://www.england.nhs.uk/wp-

content/uploads/2012/12/compassion-in-practice.pdf (accessed 20 November 2016)

Herdtner S (2000) Using Therapeutic Touch in Nursing Practice. Orthopaedic Nursing. 77-82

Kozier B, Erb G, Berman A, Snyder S., Harvey S, Morgan-Samuel H (2012) Fundamentals of Nursing: Concepts, Process and Practice. 2nd edn. Pearson Education Limited, Harlow

O'Lynn C \& Krautscheid L (2011) How Should I Touch You? A Qualitative Study of Attitudes on Intimate Touch in Nursing Care. American Journal of Nursing. 111(3): 24-31

Quiddington J (2009) Breaking Significant News. In: Glasper A, McEwing G \& Richardson J (eds) Foundation Skills for Caring: Using Student-centred Learning. Palgrave Macmillan, Hampshire. 55-67

Russell P (1999) Social Behaviour and Professional Interactions. In Hogston R \& Simpson PM (eds) Foundation of Nursing Practice. Palgrave, Hampshire. 267-293

Russell P (2011) Dying, Death and Spirituality. In Hogston R \& Marjoram B (eds) Foundation of Nursing Practice: Themes, Concepts and Frameworks. 4th edn. Palgrave Macmillan, Hampshire. 291-318

Senderovich H, Ip ML, Berall A, Karuza J, Gordon M, Binns M, Wignarajah S, Grossman D, Dunal L (2016) Therapeutic Touch in a Geriatric Palliative Care Unit A Retrospective Review. Complementary Therapies in Clinical Practice. 24: 134-138

Sharples N (2013) Relationship, Helping and Communication Skills. In: Brooker C, Waugh A (eds) Nursing Practice: Fundamentals of holistic Care. Mosby Elsevier, London. 193-218

Skills for Care (2016) The Care Certificate: Communication.

http://www.skillsforcare.org.uk/Documents/Learning-and-development/Care-

Certificate/Standard-6.pdf (accessed 20 November 2016)

Skills for Care and Skills for Health (2013) Code of Conduct for Healthcare Support Workers and Adult Social Care Workers in England.

http://www.skillsforhealth.org.uk/images/services/code-ofconduct/Code\%20of\%20Conduct\%20Healthcare\%20Support.pdf (accessed 20 November 2016) 
Tabatabaee A, Tafreshi ZT, Rassouli M, Aledavood SA, AlaviMajd H, Farahmand SK (2016) Effect of Therapeutic Touch in Patients With Cancer: A Literature Review. Medical Archives. 70(2): 142-147 